\title{
Status of parasitism in donkeys of project and control areas in central region of Ethiopia: a comparative study
}

\author{
Desalegne Abebew ${ }^{1}$, Bojia Endebu ${ }^{2}$ and Ayele Gizachew ${ }^{2}$ \\ ${ }^{1}$ Wollo University, College of agriculture and veterinary medicine, \\ ${ }^{2}$ Addis Ababa University, School of Veterinary Medicine \\ Corresponding author: dabebew@gmail.com
}

\begin{abstract}
The study was undertaken with the aim of comparing the status of parasitism in donkeys in the Donkey Health and welfare Project intervention (Bereh, Ada and Boset) and Control (Yekaduda, Gerado and Meki) areas of, Central Ethiopia, in 2005. Parasites are prime problem of donkeys among other problems including wound and other infectious and noninfectious diseases. The methods applied included coproscopy, packed cell volume determination, live weight estimation and body condition scoring. A total of 648 donkeys were sampled from both control (324) and project (324) study areas. Qualitative faecal worm egg analysis revealed the prevalence of different helminthes in project and control areas to be respectively, Strongyles spp. (22.8\% \& 49.7\%), Oxyruis equi (4.6\% \& 6.5\%), Anaplocephala spp. $(2.2 \% \& 5.6 \%)$, Fasciola spp. $(6.5 \% \& 7.7 \%)$ and Gastrodiscus aegypticus $(1.9 \%$ $\& 6.2 \%)$. The mean prevalence in the project and control areas was $22.9 \%$ and $29.0 \%$, respectively. Quantitative faecal egg analysis revealed that the mean epg in the project and control areas to be 433.6 and 777.2 eggs per gram of faeces (epg), respectively. There was a significant difference $(\mathrm{p}<0.0001)$ in helminth egg counts between the project and control areas. The value of mean packed cell volume (PCV) in the project and control areas was $35.1 \%$ and $33.2 \%$ respectively. Body condition scoring and live weight estimation had no significant difference between the project and control areas. In conclusion, intervention by the DHWP has significantly reduced the prevalence and intensity of helminth parasitism in donkeys but this has not yet translated to improvement in body condition of the animals.
\end{abstract}

Keywords: Donkey, Central, Ethiopia, Helminth parasite, Prevalence.

\section{Introduction}

The donkey has spent hundreds of years being used by man. In spite of this fact, little attempt has been made to study any aspect of this equine (Svendsen, 1997). Of the 41.5 million donkeys known to exist in the world, 40 million, 
which is equivalent to $96.2 \%$, are found in developing countries (Fielding, 1991). According to FAO, the donkey population in Ethiopia is 3.9 million (FAO, 1985). They account for over 50\% of the animal energy scenario in the country (Feseha Gebreab et al., 1997). Donkeys have reduced the domestic transport burden of especially women and have created employment and income generating opportunities for many people (Pearson, 2000). Although donkeys are often described as hardy and resistant animals, they do succumb to a number of health problems. The most important ones are parasitic disease especially gastrointestinal parasites, harness sores, sarcoides and infectious diseases such as anthrax (Svendsen, 1994).

Studies of helminth parasites in working donkeys have uncovered a diversity of helminth species (Matthee et al. 2000; Ayele Gizachew et al. 2006). These studies had shown that helminths in working donkeys were highly prevalent, infection intensities were very high and they are the major health problems of working donkeys in developing countries. In Ethiopia various studies have shown that donkeys commonly harbor gastrointestinal parasites such as large and small Strongyles, Ascarides, Pinworms, bots, stomach worms, lung worms, tapeworms and liver flukes (Feseha Gebreab et al., 2000). The Donkey Health and welfare project (DHWP) in Ethiopia is working in different parts of the country to help improve the health and welfare of the animals. In the areas of intervention, anthelmintic treatments are commonly undertaken free of charge to combat helminth parasitism in donkeys.

However, parasites fauna/profile of donkeys in the intervention sites was not determined. Therefore the objectives of this work were to conduct a comparative study of gastrointestinal parasites profile \& other associated factors of donkeys between project and control areas and to compare the impact of tactical deworming using pre-indicators between these two areas.

\section{Materials and methods}

\section{Study area}

The study was conducted in six woredas grouped into two study blocks: Bereh, Ada and Boset (DHWP areas) and Yekaduda, Gerado and Meki (Control areas) of Central Ethiopia. The two blocks generally have similar agroclimatic condition. 


\section{Study animals}

The study animals were donkeys in six woredas of Central Ethiopia, maintained under traditional small ho1der extensive management production system. A total of 648 working donkeys were sampled irrespective of age and sex randomly, 108 from each of the two study blocks. In addition, blood and faecal samples were also collected monthly. The age of the selected donkeys was determined using the incisor eruption times and wear (Crane, 1997). Donkeys were grouped into three age categories: donkeys under two years were classed as young $(\mathrm{n}=216)$, those in range of two to ten years were classed as adult $(n=216)$ and those beyond ten years were classed as old $(n=216)$.

\section{Study design}

\section{Coproscopy}

Faecal samples were collected directly from the rectum using arm length gloves. Specimens were labeled with identification number and were stored at $4^{\circ} \mathrm{c}$ till laboratory examination was done. Qualitative and quantitative faecal helminthe egg examinations were done by employing the modified McMaster method (Kassai, 1999). Qualitative identification of Oxyruis equi was done by Scotch tape method. Ovaculture was conducted for specific identification and quantification of GIT helminths. About $3 \mathrm{gm}$ of pooled/mixed sample was taken for ovaculturing of 21 samples from each Control and Project areas. Modified Barman technique was used to count the larvae (L3) and ascertain the occurrence of lung worm infection (Sloss et al., 1994). Identification of larvae (L3) was based on specific morphological traits set by Poynter (1970).

\section{Packed cell volume determination}

Blood samples were taken from marginal ear vein of donkeys using heparinized capillary tube to determine packed cell volume (PCV). The vacant end was sealed with sealant. The capillary tube was centrifuged at $1500 \mathrm{rpm}$ for 5 minutes then the value of PCV was determined using a microhaematocrite reader.

\section{Live weight estimation}

Live weight of donkeys was estimated using one of the commonest techniques adopted: measuring heart girth and body length with predictions taken from normograms specifically developed for use in working donkeys (Pearson and Ouassat, 1996) in Morocco.

Ethiop. Vet. J., 2011, 15 (2), 45-55 


\section{Body condition scoring}

Body condition has been one of the tools the Donkey Health and Welfare Project (DHWP) uses for tactical deworming. It was also considered here as a marker of variation between Project and control areas. Condition score was assessed subjectively using a scale from 1 (emaciated), 2 (thin), 3 (good), 4(fat) to 5 (obese) (Svendsen, 1997).

\section{Data analysis}

Descriptive statistics was used to calculate the prevalence of the different GIT Helminths. (SPSS for Windows, release 11.5.0, 2002) was used to analyze the effect of different factors on the epg of helminths and PCV.

\section{Result}

\section{Coproscopy}

\section{Qualitative faecal egg analysis in project and control areas}

A total of 648 faecal samples (324) from project and (324) from control areas were collected and examined for the presence of GIT helminths. The mean prevalence in the project block was significantly lower than that in control area. There was a significance difference $(\mathrm{p}<0.001)$ in helminths prevalence between the project and control areas (Table 1). The mean prevalence distribution of helminthes in the project area showed $23.3 \%$ in Ada, followed by Boset $(22.8 \%)$ and in Bereh (22.7\%) and the difference was not statistically significant. In the control areas the epg prevalence was $30.1 \%$ in Yekaduda, 28.9\% in Meki and $28.1 \%$ in Gerado. There was no statistical difference among the three woredas (Table 2).

\section{Quantitative faecal egg analysis in project and control areas}

The mean epg (433.6) in the project area was significantly lower than that of control (777.2) area $(\mathrm{P}<0.0001)$. The vast majority of eggs were that of strongyle parasites followed by parascaris (Table 3).

\section{Differential larva counts}

Pooled samples from each sex and age of donkeys in each woreda were subjected to coproculture. Nine types of helminth parasite larvae were identified; the highest percent goes to S.vulgaris and Trichonema species which account 
for $100 \%$ in both control and project sites. The least in the project area was Dictyocaulus arnifield (22.2\%) and in the control areas S.equinus (33.3\%) and T.axei (33.3\%) were the least encountered (Table 4).

\section{Packed cell volume (PCV) determination}

The value of mean packed cell volume in project and control areas was $35.1 \%$ and $33.2 \%$, respectively (Table 5). And the difference was not statistically significant. The value of PCV was not statistically different between parameters of sex, age, and body condition. The minimum and maximum values of PCV in the Project area were $24.0 \%$ and $46.0 \%$ respectively. In control areas, the minimum and maximum PCV values were $28.0 \%$ and $39.0 \%$ respectively.

\section{Body condition scoring and live weight estimation}

The donkeys' condition was scored on a scale of 1 to 5 (Svendsen, 1997). The mean body scores for donkeys in the project and control areas were 1.88 and 1.78 respectively. There was no significant difference between body condition scores of donkeys in the project and control areas. There was no significant difference between the mean live weight of donkeys in the project areas and control areas, data not shown.

Table 1. Prevalence of specific helminths in project and control areas based on faecal examination.

\begin{tabular}{|c|c|c|c|c|c|c|c|}
\hline \multirow{2}{*}{$\begin{array}{l}\text { Study } \\
\text { area }\end{array}$} & \multirow{2}{*}{$\begin{array}{l}\text { Total No. } \\
\text { of } \\
\text { animals } \\
\text { examined }\end{array}$} & \multicolumn{6}{|c|}{ Specific helminths parasites } \\
\hline & & $\begin{array}{l}\text { Strongyle } \\
\text { Spp. }\end{array}$ & $\begin{array}{l}\text { Parascaris } \\
\text { equorem }\end{array}$ & $\begin{array}{l}\text { Oxyuris } \\
\text { equi }\end{array}$ & $\begin{array}{l}\text { Anapro } \\
\text { cephala } \\
\text { spp. }\end{array}$ & $\begin{array}{l}\text { Fasciola } \\
\text { Spp. }\end{array}$ & Gastrodiscus \\
\hline \multirow[t]{2}{*}{ Project } & 324 & 319 & 74 & 15 & 7 & 21 & 9 \\
\hline & $\%$ & 98.5 & 22.8 & 4.6 & 2.2 & 6.5 & 19.0 \\
\hline \multirow[t]{2}{*}{ Control } & 324 & 324 & 161 & 21 & 18 & 25 & 20 \\
\hline & $\%$ & 100 & 49.7 & 6.5 & 5.6 & 7.7 & 6.2 \\
\hline
\end{tabular}

Ethiop. Vet. J., 2011, 15 (2), 45-55 
Desalegne Abebew, et al.

Table 2. Mean prevalence of helminths in project and control areas.

\begin{tabular}{llccc}
\hline & Study woreda & $\begin{array}{l}\text { Total No. of } \\
\text { donkeys }\end{array}$ & Positive Cases & $\begin{array}{c}\text { Mean } \\
\text { prevalence }\end{array}$ \\
\hline Project & Bereh & 108 & 22.7 & 22.7 \\
& Ada & 108 & 25.2 & 23.3 \\
& Boset & 108 & 24.7 & 22.8 \\
Control & Yekaduda & 108 & 32.5 & 30.1 \\
& Gerado & 108 & 30.8 & 28.1 \\
& Meki & 108 & 31.2 & 28.9 \\
\hline
\end{tabular}

Location= page 4

Table 3. Mean epg of different helminthes in Project and Control areas.

\begin{tabular}{lcccccc}
\hline Study & \multicolumn{5}{c}{ Specific helminthes parasites } \\
\cline { 2 - 7 } Area & Strongyles & Parascaris & Oxyuris & Anaprocephala & Fasciola & Gastrodiscus \\
\hline Project & 2528.2 & 70.7 & 8.9 & 2.0 & 5.4 & 3.4 \\
Control & 4999.1 & 129.4 & 13.4 & 9.9 & 7.1 & 9.6 \\
\hline
\end{tabular}

Location= page 4

Table 4. Relative percentage of larvae of different helminth parasites recovered from coproculture of 21 samples in each Project and Control.

\begin{tabular}{lcc}
\hline Types of larvae & Relative percentage of larvae count \\
\cline { 2 - 3 } & Project & Control \\
\hline Stronguluss Vulgaris & 100 & 100 \\
Strongyles edenatus & 88.9 & 88.9 \\
Strongulus equinus & 44.4 & 33.3 \\
Cyathostomum spp & 100 & 100 \\
Tridontophorus spp & 44.4 & 55.5 \\
Trichostronglus axei & 33.3 & 33.3 \\
Strongyloides westeri & 44.4 & 77.8 \\
Free living nematode & 33.3 & 66.7 \\
Dictyocaules arnfieldi & 22.2 & 66.7 \\
\hline
\end{tabular}

Location= page 5 
Table 5. Mean PCV value of the donkeys in different study areas: N=108 for each woreda.

\begin{tabular}{llllll}
\hline Study area & & Mean & Median \pm SD & Minimum & Maximum \\
\hline \multirow{2}{*}{ Project } & Bereh & 34.7 & $39.0 \pm 3.5$ & 28.0 & 45.0 \\
& Ada & 35.46 & $35.0 \pm 3$. & 28.0 & 45.0 \\
& Boset & 35.2 & $35.0 \pm 3.8$ & 24.0 & 46.0 \\
& & & & \\
\multirow{4}{*}{ control } & Yekaduda & 33.6 & $34.0 \pm 2.1$ & 28.0 & 39.0 \\
& Gerado & 32.3 & $32.0 \pm 1.6$ & 29.0 & 35.0 \\
& Meki & 33.7 & $33.0 \pm 2.6$ & 28.0 & 39.0 \\
\hline
\end{tabular}

Location $=$ page 5

\section{Discussion}

Qualitative faecal epg analysis was conducted to differentiate the types of parasites and their relative occurrence. In both project and control areas, six types of helminths eggs were identified, namely Strongyles spp, Parascaris equorum, Oxyruis equi, Gastrodiscus aegypticus, Anaplocephala spp and Fasciola spp. Donkeys sampled in the control areas were $100 \%$ positive for Strongyles spp. egg, but in the project areas, the maximum occurrence of Strongyles spp was $98 \%$. This is in consistent with the findings of Feseha et al. (2000) and Bergeon (1968). Their work revealed a high rate of infection by strongylosis in equine population of Ethiopia. However a relatively low total prevalence of Gastrodiscus and Fasciola spps were observed in both project and control areas.

The mean prevalence in the project areas is $22.9 \%$ while in control areas it is $29.0 \%$. The lower prevalence in project areas could be the result of the intervention programs on the control of helminth parasitism which is consistent with the finding of Osnas and Lively (2004). According to Soulsby (1982), an epg of 500 suggest mild strongyle infection, 500-1000 a moderate infection and above 1000 a severe infection in horses. On this basis, the majority of working donkeys in both areas are severely infected with helminths. When a comparison assessment was made between the mean epg of donkeys sampled from project (433.6 epg) and control (777.2 epg) areas, there was a statistically significant difference. This could be attributed to the effect of anthelmintic treatments applied in the project areas. However, this result is not in agreement with the work of Andrew (2003) in Morocco. 
Even though there is such difference in mean epg between the two study groups, no difference was observed in PCV. The prevalence of Strongyles vulgaris was high accounting for $100 \%$ in differential larval count both in the project and control areas. As this parasite is the most pathogenic helminth parasite of equines, it might explain the similarity in PCV between animals of the two blocks. This is in agreement with the work done by Feseha Gebreab, et al. (2000) in West Shoa Adminstretive Region, Ethiopia.

The prevalence of Trichostrongylus axei, as determined from differential ovaculture was $33.3 \%$ in both control and project areas. But it is lower than the report of Pandey, et al. (1980) in Morocco (80.9\%). This may be attributed to its multiple hosts which might have decreased its prevalence in equines. In both the project and control areas animals of different species were kept together in the same grazing field, thereby lowering the share of equines.

The mean live weight estimation between the project $(123.5 \mathrm{~kg})$ and control $(123.6 \mathrm{~kg})$ was almost similar. The mean worm epg count difference between control and project areas was not manifested in terms of the live weight. This could be due to the similarity in the management aspect. This result is in agreement with Smith, et al. (2005). Smith, et al. (2005) also reported the same result in Central Ethiopia. They showed that donkeys with heliminth infections were able to maintain statistically similar weight gains to donkeys that had received intensive anthelmintic treatment. Significantly better weight gains were only achieved when anthelmintic and feed supplementations were combined.

A comparative assessment of body condition score of donkeys revealed almost similar result between the project (1.88) and control areas (1.78). Variation in body condition score could be used as a reliable indicator of parasitic burden which could be used by owners to identify donkeys with acute therapeutic requirements for anthelmintic (Agajie, et al., 2000). The absence of a significant difference in the condition scores of donkeys between the project and control areas indicate a trend that does not show improvement to anthelmintic treatment. However, this could be due to the effect of other contributing factors such as nutrition and the amount of work which have a major effect on body condition. This result is in agreement with the study of Andrew (2003) in Morocco. 
In conclusion, this study has clearly indicated worm egg counts in donkeys from project areas were suppressed to low infection levels when compared to donkeys from control areas that had not received anthelmintic and maintained medium infections. However, this reduction in parasitic burden was not maintained in terms of increased live weight or improved PCV. It is obvious that strategic anthelmintic treatments could be more effective to control parasites through an entire grazing season if all the donkeys from the same region are systematically treated. Resistance to this anthelmintic may also well develop if it becomes more widely used to control worm burdens. The present study has revealed the presence of a range of helminths which are representative of the important pathogenic parasites of donkeys. A detailed study of the epidemiology, pathogenicity, and the anthelminitc resistance status of prevailing parasites is highly recommended.

\section{Acknowledgments}

This study was financially supported by the Donkey Sanctuary. The authors are grateful to the Faculties of Veterinary Medicine of Addis Ababa University for their support and facilities. The technical assistance of the Donkey Health and Welfare Project staff in Ethiopia is highly appreciated with thanks.

\section{References}

Agajie, T., Tarnirat, D., Pearson, R. A. and Temesgen, T., 2000. Socio economic circumstances of donkey use and management in the rural and urban areas of central part of Ethiopia. In: D. Smith, A. Tesfaye and L. Move (eds), Proceedings of a work shop on promoting peri urban livelihoods, Through Better Donkey Welfare, October 2000, Debre Zeit, Ethiopia, pp. 16-25.

Andrew, G., 2003. Assessing the efficacy of an anthelmintic programme on the health and welfare of working equines in Morocco. In: a Drought Animal News No 39, $6-14$.

Bergeon, P., 1968. Report to the government of Ethiopia on Veterinary Parasitology, No. 2458, FAO, Rome.

Crane, M., 1997. Medical. In: Svendsen E (Ed): The professional hand book of the Donkey, 3rd ed. Whittet Books LTD, W140By, London, pp. 29.

FAO, 1985. Production year book 39. Food and agriculture organization, Acadamic Press, Rome, Italy.

Ethiop. Vet. J., 2011, 15 (2), 45-55 
Fessehan, B., 1993. Use of equines in Ethiopia. In: Proceedings of the fourth national livestock improvement conference held in Addis Ababa, pp. 51-58.

Fielding, D., 1991. The number and distribution of equines in the world. Donkey, mules and horses in tropical agricultural development. Proceeding of a collquium on donkeys, mules and horses (eds), D, Fielding and R. A. Pearson. (University of Edinburgh, Centre for Tropical veterinary Medicine, UK.), pp. 62 -66.

Gebreab, F., 1997. Disease and health problems of donkeys abroad. In: Svendsen, (eds), The professional Hand Book of Donkeys Edition. pp. 207- 226.

Gebreab, F., Shiferaw, Y. and Worsene, A., 2000. Survey on helmintnosis of equines in Wenchi ,West Shewa Administrative Region, Ethiopia In: Smith, D., Tesfaye, A. and More, L. (eds), Alleviating poverty in peri-urban Ethiopia by improving the health, (welfare and management of donkeys proceedings of a work shop held at Debre Zeit, Ethiopia), pp. 128- 138.

Gizachew, A., Gebreab, F., Endebu, B. and Joe, A., 2006. Prevalence of gastrointestinal parasites of donkeys in Dugda Bora District, Ethiopia, Livestock Research for Rural Development. 18, 11, (http://www.cipav.org.co/lrrd/lrrd18/10/ayel18136. htm).

Kassai, T., 1999. Veterinary Helminthology. London: Reed Educational and professional publishing Ltd. pp. 156-159.

Matthee, S., Krecek, R.C. and Milne, S.A., 2000. Prevalence and biodiversity of helminth parasites in donkeys from South African. J. Vet. Parasitol., 86, 756-762.

Osnas, E. and Lively, E., 2004. Parasite dose, prevalence of infection and local adaptation in a host-parasite system. Parasitology, 128, 223-228.

Pandey, S. V., 1980. Seasonal prevalence of Strongylus vulgaris in the mesentery of donkey in Morroc. J. Vet. Parasitol., 7, 350-361.

Pearson, R. A. and Ouassat, M., 1996. Estimation of the live weight and body condition of working donkeys in Morocco. The Veterinary Record, 138, 229-233.

Pearson, R. A., 2000. Introduction to the project use and management of donkeys by poor society on peri-urban areas in Ethiopia. In: D. G. Smith, T. Agajie and L. More (eds) alleviating poverty in peri-urban Ethiopia by improving the health, welfare, management of donkeys. Promoting peri-urban livelihoods through better donkey welfare. Proceedings of workshop held at Debre Zeit, Ethiopia, October 2000, Edinburgh, CTVM, pp. 35. 
Poynter, D., 1970. Some observations on the nematode parasites of horse. In: J.T. Bryans and H. Gerber (eds), Equine infectious diseases proceedings 2nd international conference on equine infectious diseases Paris, 1969. (Basel, Switzer and, S. Karger), pp. 269-289.

Sloss, M., Kemp, R. and Zajac, A., 1994. Veterinary clinic parasitlogy. 6th edn, (AInes, Iowa state University Press).

Smith, D. G., Mengistu, A., Yoespn, S., Nega, T., Qwdie, W., Kassahun, W., Taye, B. and Flfew, T., 2005. The effect of providing feed supplementation and anthelmintic to donkeys during late pregnancy and lactation on live weight and survival dams and their foals in central Ethiopia. Trop. Anim. Hlth. Prod., 10, 23-12.

Soulsby, E. J. L., 1982. Helminths, arthropods and protozoa of domesticated animals (7th ed). ELBS, London. pp. 809.

Svendsen, E. D., 1994. The main types of parasites affecting donkeys health in various parts of the world, in proceedings of and collquin on working equines (eds), Bakkoury M. E. and Prentis R. A., (Institute Agronolriique et Veterinaire Hassan , Rabat, Morocco), pp. 23-24.

Svendsen, E. D., 1997. Parasites Abroad. In: Svendsen B. E. (eds). The Professional hand book of the donkey 3rd edition whittest Books, London, pp. 227 -238. 